\section{UPDATE AleRT}

\section{Update Alert 3: Masks for Prevention of Respiratory Virus Infections, Including SARS-CoV-2, in Health Care and Community Settings}

This is the third update alert for a living rapid review on the use of masks for prevention of respiratory virus infections, including severe acute respiratory syndrome coronavirus 2 (SARS-CoV-2), in health care and community settings (1). Searches were updated from 3 August to 2 October 2020 using the same search strategies as the original review. The update searches identified 407 citations. One study (2) on the use of masks and SARS-CoV-2 infection in a community setting and 2 studies $(3,4)$ in health care settings were added (Supplement Tables 1-3).

The evidence on mask use and risk for SARS-CoV-2 infection in community settings was previously assessed as insufficient on the basis of 1 study with methodological limitations (5). A new case-control study in Thailand enrolled asymptomatic contacts of patients with coronavirus disease 2019 (COVID-19) from 3 large community clusters (211 case patients and 839 uninfected control participants) (2). Wearing a mask all of the time versus no use was associated with decreased risk for SARS-CoV-2 infection after adjustment for age; sex; exposure to contact; sharing of dishes, cups, or cigarettes; and handwashing (adjusted odds ratio [OR], 0.23 [95\% Cl, 0.09 to 0.60$]$ ). However, inconsistent use was not associated with decreased risk (adjusted OR, $0.87[\mathrm{Cl}, 0.41$ to 1.84]). Mask type (medical mask only, nonmedical mask only, or both) was not independently associated with risk for SARSCoV-2 infection $(P=0.54)$. Methodological limitations included potential recall bias. In addition, data were missing or had potential discrepancies and control for exposures was limited. Therefore, the strength of evidence for mask use and risk for SARS-CoV-2 in community settings remained insufficient (Supplement Table 4).

The evidence on mask use and risk for SARS-CoV-2 infection in health care settings was also previously assessed as insufficient on the basis of 1 study with methodological limitations (6). Two new studies reported on mask use in health care settings $(3,4)$. One cohort study $(n=903)$ of hospital health care workers in Italy exposed to a patient with COVID-19 reported an imprecise estimate, with no statistically significant difference between mask use (FFP2 or FFP3 [equivalent to N95 or N99] or surgical mask) versus no mask use and risk for COVID-19 (adjusted OR, 1.6 [Cl, 0.9 to 2.9]). Use of an FFP2 or FFP3 mask versus a surgical mask was associated with increased risk for COVID-19 (adjusted OR, $7.1[\mathrm{Cl}, 3.0$ to 16.7]) (4). A case-control study of hospital physicians in Bangladesh (98 case patients with COVID-19 and 92 control participants) also reported an imprecise estimate for medical mask use versus no mask use and risk for COVID-19 (adjusted
OR, $1.40[\mathrm{Cl}, 0.30$ to 6.42]). However, N95 mask use versus no mask use was associated with decreased risk for COVID-19 during aerosol-generating procedures $(\mathrm{OR}, 0.37[\mathrm{Cl}, 0.16$ to $0.87]$ ) (3). Both studies had serious methodological limitations, including potential recall bias and data discrepancies. In addition, 1 study (4) controlled only for age, and it was unclear what confounders were controlled for in the other study (3). Therefore, evidence for mask use versus nonuse and comparing masks types in health care settings remained insufficient (Supplement Table 4). There were no new studies on the effectiveness and safety of mask reuse or extended use.

\section{Roger Chou, MD}

Tracy Dana, MLS

Rebecca Jungbauer, DrPH

Chandler Weeks, MPH

Pacific Northwest Evidence-based Practice Center and Oregon Health \& Science University, Portland, Oregon

Disclaimer: The authors of this manuscript are responsible for its content. Statements in the manuscript do not necessarily represent the official views of or imply endorsement by AHRQ or HHS.

Disclosures: Disclosures can be viewed at www.acponline.org /authors/icmje/ConflictOfInterestForms.do?msNum=L20-1292.

Corresponding Author: Roger Chou, MD, Oregon Health \& Science University, 3181 SW Sam Jackson Park Road, Mail Code BICC, Portland, OR 97239; e-mail, chour@ohsu.edu.

doi:10.7326/L20-1292

\section{References}

1. Chou R, Dana T, Jungbauer R, et al. Masks for prevention of respiratory virus infections, including SARS-CoV-2, in health care and community settings: a living rapid review. Ann Intern Med. 2020;173:542-555. [PMID: 32579379] doi:10.7326/M20-3213

2. Doung-Ngern P, Suphanchaimat R, Panjangampatthana $A$, et al. Casecontrol study of use of personal protective measures and risk for SARS-CoV 2 infection, Thailand. Emerg Infect Dis. 2020;26:2607-2616. [PMID: 32931726] doi:10.3201/eid2611.203003

3. Khalil MM, Alam MM, Arefin MK, et al. Role of personal protective measures in prevention of COVID-19 spread among physicians in Bangladesh: a multicenter cross-sectional comparative study. SN Compr Clin Med. 2020:1-7. [PMID: 32904377] doi:10.1007/s42399-020-00471-1

4. Piapan L, De Michieli P, Ronchese F, et al. COVID-19 outbreak in healthcare workers in hospitals in Trieste, North-east Italy. J Hosp Infect. 2020. [PMID: 32805309] doi:10.1016/j.jhin.2020.08.012

5. Wang $Y$, Tian $H$, Zhang $L$, et al. Reduction of secondary transmission of SARS-CoV-2 in households by face mask use, disinfection and social distancing: a cohort study in Beijing, China. BMJ Glob Health. 2020;5. [PMID: 32467353] doi:10.1136/bmjgh-2020-002794

6. Chatterjee P, Anand T, Singh KJ, et al. Healthcare workers \& SARS-CoV-2 infection in India: a case-control investigation in the time of COVID-19. Indian J Med Res. 2020;151:459-467. [PMID: 32611916] doi:10.4103/ijmr.IJMR _2234_20 